\title{
Anti Q-Fuzzy HX Group and Its Lower Level Sub HX Groups
}

\author{
R.Muthuraj , K.H.Manikandan, M.S.Muthuraman, P.M.Sitharselvam \\ Department of Mathematics, PSNA College of Engineering and Technology, \\ Dindigul-624 622, Tamilnadu, India.
}

\begin{abstract}
In this paper, we redefine the definition of a fuzzy HX group and define a new algebraic structure of Q-fuzzy HX group and anti Q-fuzzy HX subgroup and some related properties are ivestigated. We establish the relation between Q-fuzzy HX group and anti Q-fuzzy HX group of a HX group. The purpose of this study is to implement the fuzzy set theory and group theory in anti Q-fuzzy HX subgroups. Characterizations of lower level subsets of an anti Q-fuzzy HX subgroup of a HX group are given.
\end{abstract}

\section{Keywords}

Fuzzy set , Q-fuzzy set, fuzzy subgroup , Q-fuzzy subgroup, anti-Q fuzzy subgroups. anti-Q fuzzy HX subgroups.

\section{AMS Subject Classification (2000): 20N25, 03E72, 03F055 , 06F35, 03G25.}

\section{Introduction}

K.H.Kim introduce the concept of intuitionistic Q-fuzzy semi prime ideals in semi groups and Osman kazanci, sultan yamark and serife yilmaz introduce the concept of intuitionistic Q-fuzzy R-subgroups of near rings and F.H. Rho, K.H.Kim, J.G Lu introduce the concept of intuitionistic Q-fuzzy subalgebras of BCK / BCI algebras. A.Solairaju and R.Nagarajan introduce and define a new algebraic structure of Q-fuzzy groups. Li Hongxing introduce the concept of HX group and the authors Luo Chengzhong, Mi Honghai , Li Hongxing introduce the concept of fuzzy HX group. In this paper we define a new algebraic structure of Q-fuzzy HX group and anti Q-fuzzy HX subgroup and study some their related properties.

\section{Preliminaries}

In this section we site the fundamental definitions that will be used in the sequel. Through out this paper, $\mathrm{G}=(\mathrm{G}, *)$ is a group, e is the identity element of $\mathrm{G}$, and $\mathrm{xy}$, we mean $\mathrm{x} * \mathrm{y}$.

\subsection{Definition}

In $2^{\mathrm{G}}-\{\phi\}$, a nonempty set $\vartheta \subset 2^{\mathrm{G}}-\{\phi\}$ is called a HX group on $\mathrm{G}$, if $\vartheta$ is a group with respect to the algebraic operation defined by $\mathrm{AB}=\{\mathrm{ab} / \mathrm{a} \in \mathrm{A}$ and $\mathrm{b} \in \mathrm{B}\}$, which its unit element is denoted by $\mathrm{E}$.

\subsection{Definition}

Let $\mathrm{X}$ be any non empty set. A fuzzy subset $\lambda$ of $\mathrm{S}$ is a function

$\lambda: X \rightarrow[0,1]$

\subsection{Definition}

A fuzzy set $\lambda$ is called fuzzy HX subgroup of a HX group $\vartheta$ if for $\mathrm{A}, \mathrm{B} \in \vartheta$,
(i) $\lambda(\mathrm{AB}) \geq \min \{\lambda(\mathrm{A}), \lambda(\mathrm{B})\}$
(ii) $\lambda\left(\mathrm{A}^{-1}\right)=\lambda(\mathrm{A})$.

\subsection{Definition}

A fuzzy set $\lambda$ is called an anti fuzzy HX subgroup of a HX group $\vartheta$ if $\mathrm{A}, \mathrm{B} \in \boldsymbol{\vartheta}$,

$$
\begin{aligned}
& \text { (i) } \lambda(\mathrm{AB}) \leq \max \{\lambda(\mathrm{A}), \lambda(\mathrm{B})\}, \\
& \text { (ii) } \lambda\left(\mathrm{A}^{-1}\right)=\lambda(\mathrm{A})
\end{aligned}
$$

\subsection{Definition}

Let $\mathrm{Q}$ and $\vartheta$ be any two sets. A mapping

$$
\lambda: \vartheta \times Q \rightarrow[0,1] \text { is called a Q-fuzzy set in } \vartheta
$$

\subsection{Definition}

A Q-fuzzy set $\lambda$ is called Q-fuzzy HX subgroup of a HX group $\vartheta$ if for $\mathrm{A}, \mathrm{B} \in \mathcal{\vartheta}$ and $\mathrm{q} \in \mathrm{Q}$,
(iii) $\lambda(\mathrm{AB}, \mathrm{q}) \geq \min \{\lambda(\mathrm{A}, \mathrm{q}), \lambda(\mathrm{B}, \mathrm{q})\}$
(iv) $\lambda\left(\mathrm{A}^{-1}, \mathrm{q}\right)=\lambda(\mathrm{A}, \mathrm{q})$. 


\subsection{Definition}

A Q-fuzzy set $\lambda$ is called an anti Q-fuzzy HX subgroup of a HX group $\vartheta$ if $A, B \in \vartheta$ and $q \in Q$,

$$
\begin{aligned}
& \text { (iii) } \lambda(\mathrm{AB}, \mathrm{q}) \leq \max \{\lambda(\mathrm{A}, \mathrm{q}), \lambda(\mathrm{B}, \mathrm{q})\} \text {, } \\
& \text { (iv) } \lambda\left(\mathrm{A}^{-1}, \mathrm{q}\right)=\lambda(\mathrm{A}, \mathrm{q}) .
\end{aligned}
$$

\section{Properties of anti Q-fuzzy HX subgroup}

In this section, we discuss some of the properties of anti Q-fuzzy HX subgroup.

\subsection{Theorem}

$$
\text { Let } \lambda \text { be an anti Q-fuzzy HX subgroup of a }
$$

HX group $\vartheta$ then

i. $\lambda(A, q) \geq \lambda(E, q)$ for all $A \in \vartheta, q \in Q$ and $E$ is the identity element of $\vartheta$.

ii. The subset $H=\{A \in \vartheta / \lambda(A, q)=\lambda(E, q)\}$ is a sub HX group of $\vartheta$.

Proof

(i) Let $A \in \vartheta$ and $q \in Q$.

$$
\begin{aligned}
\lambda(\mathrm{A}, \mathrm{q}) & =\max \{\lambda(\mathrm{A}, \mathrm{q}), \lambda(\mathrm{A}, \mathrm{q})\} \\
& =\max \left\{\lambda(\mathrm{A}, \mathrm{q}), \lambda\left(\mathrm{A}^{-1}, \mathrm{q}\right)\right\} \\
& \geq \lambda\left(\mathrm{AA}^{-1}, \mathrm{q}\right) \\
& =\lambda(\mathrm{E}, \mathrm{q}) . \\
\lambda(\mathrm{A}, \mathrm{q}) & \geq \lambda(\mathrm{E}, \mathrm{q}) \text { for all } \mathrm{A} \in \vartheta .
\end{aligned}
$$

(ii) Let $H=\{A \in \vartheta / \lambda(A, q)=\lambda(E, q)\}$.

Clearly $\mathrm{H}$ is non-empty as $\mathrm{E} \in \mathrm{H}$. Let $\mathrm{A}, \mathrm{B} \in \mathrm{H}$.

Then, $\lambda(A, q)=\lambda(B, q)=\lambda(E, q)$.

$$
\begin{aligned}
\lambda\left(\mathrm{AB}^{-1}, \mathrm{q}\right) & \leq \max \left\{\lambda(\mathrm{A}, \mathrm{q}), \lambda\left(\mathrm{B}^{-1}, \mathrm{q}\right)\right\} \\
& =\max \{\lambda(\mathrm{A}, \mathrm{q}), \lambda(\mathrm{B}, \mathrm{q})\} \\
& =\max \{\lambda(\mathrm{E}, \mathrm{q}), \lambda(\mathrm{E}, \mathrm{q})\} \\
& =\lambda(\mathrm{E}, \mathrm{q})
\end{aligned}
$$

That is, $\lambda\left(\mathrm{AB}^{-1}, \mathrm{q}\right) \leq \lambda(\mathrm{E}, \mathrm{q})$ and obviously

$$
\lambda\left(\mathrm{AB}^{-1}, \mathrm{q}\right) \geq \lambda(\mathrm{E}, \mathrm{q}) .
$$

Hence, $\lambda\left(\mathrm{AB}^{-1}, \mathrm{q}\right)=\lambda(\mathrm{E}, \mathrm{q})$ and $\mathrm{AB}^{-1} \in \mathrm{H}$.
Clearly, $\mathrm{H}$ is a sub HX group of $\vartheta$.

\subsection{Theorem}

$\lambda$ is a Q- fuzzy HX subgroup of $\vartheta$, iff $\lambda^{\mathrm{C}}$ is an anti Q-fuzzy HX subgroup of $\vartheta$.

\section{Proof}

Suppose $\lambda$ is a Q-fuzzy HX subgroup of $\vartheta$. Then for all

$\mathrm{A}, \mathrm{B} \in \Theta$ and $\mathrm{q} \in \mathrm{Q}$,

$$
\lambda(\mathrm{AB}, \mathrm{q}) \geq \min \{\lambda(\mathrm{x}, \mathrm{q}), \lambda(\mathrm{B}, \mathrm{q})\}
$$

$$
\begin{aligned}
& \Leftrightarrow 1-\lambda^{\mathrm{c}}(\mathrm{AB}, \mathrm{q}) \geq \min \left\{\left(1-\lambda^{\mathrm{c}}(\mathrm{A}, \mathrm{q})\right),\left(1-\lambda^{\mathrm{c}}(\mathrm{B}, \mathrm{q})\right)\right\} \\
& \Leftrightarrow \lambda^{\mathrm{c}}(\mathrm{AB}, \mathrm{q}) \leq 1-\min \left\{\left(1-\lambda^{\mathrm{c}}(\mathrm{A}, \mathrm{q})\right),\left(1-\lambda^{\mathrm{c}}(\mathrm{B}, \mathrm{q})\right)\right\} \\
& \Leftrightarrow \lambda^{\mathrm{c}}(\mathrm{AB}, \mathrm{q}) \leq \max \left\{\lambda^{\mathrm{c}}(\mathrm{A}, \mathrm{q}), \lambda^{\mathrm{c}}(\mathrm{B}, \mathrm{q})\right\} .
\end{aligned}
$$

We have, $\lambda(\mathrm{A}, \mathrm{q})=\lambda\left(\mathrm{A}^{-1}, \mathrm{q}\right)$ for all $\mathrm{A}$ in $\vartheta$ and $\mathrm{q} \in \mathrm{Q}$,

$$
\Leftrightarrow 1-\lambda^{\mathrm{c}}(\mathrm{A}, \mathrm{q}) \quad=1-\lambda^{\mathrm{c}}\left(\mathrm{A}^{-1}, \mathrm{q}\right)
$$

Therefore, $\quad \lambda^{\mathrm{c}}(\mathrm{A}, \mathrm{q})=\lambda^{\mathrm{c}}\left(\mathrm{A}^{-1}, \mathrm{q}\right)$.

Hence $\lambda^{c}$ is an anti Q-fuzzy HX subgroup of $\vartheta$.

\subsection{Theorem}

Let $\lambda$ be any anti Q-fuzzy HX subgroup of a HX group $\vartheta$ with identity E. Then

$$
\lambda\left(\mathrm{AB}^{-1}, \mathrm{q}\right)=\lambda(\mathrm{E}, \mathrm{q}) \Rightarrow \lambda(\mathrm{A}, \mathrm{q})=\lambda(\mathrm{B}, \mathrm{q})
$$

for all $\mathrm{A}, \mathrm{B}$ in $\vartheta$ and $\mathrm{q} \in \mathrm{Q}$.

\section{Proof}

Given $\lambda$ is an anti Q-fuzzy HX subgroup of $\vartheta$ and $\lambda\left(\mathrm{AB}^{-1}, \mathrm{q}\right)=\lambda(\mathrm{E}, \mathrm{q})$

Then for all A, B in $\vartheta$ and $q \in Q$,

$$
\lambda(\mathrm{A}, \mathrm{q}) \quad=\lambda\left(\mathrm{A}\left(\mathrm{B}^{-1} \mathrm{~B}\right), \mathrm{q}\right)
$$




$$
\begin{aligned}
& =\lambda\left(\left(\mathrm{AB}^{-1}\right) \mathrm{B}, \mathrm{q}\right) \\
& \leq \max \left\{\lambda\left(\mathrm{AB}^{-1}, \mathrm{q}\right), \lambda(\mathrm{B}, \mathrm{q})\right\} \\
& =\max \{\lambda(\mathrm{E}, \mathrm{q}), \lambda(\mathrm{B}, \mathrm{q})\} \\
& =\lambda(\mathrm{B}, \mathrm{q}) .
\end{aligned}
$$

That is, $\quad \lambda(\mathrm{A}, \mathrm{q}) \leq \lambda(\mathrm{B}, \mathrm{q})$.

Now, $\lambda(B, q)=\lambda\left(B^{-1}, q\right)$, since $\lambda$ is an anti Q-fuzzy

HX subgroup of $\vartheta$.

$$
\begin{aligned}
& =\lambda\left(\mathrm{EB}^{-1}, \mathrm{q}\right) \\
& =\lambda\left(\left(\mathrm{A}^{-1} \mathrm{~A}\right) \mathrm{B}^{-1}, \mathrm{q}\right) \\
& =\lambda\left(\mathrm{A}^{-1}\left(\mathrm{AB}^{-1}\right), \mathrm{q}\right) \\
& \leq \max \left\{\lambda\left(\mathrm{A}^{-1}, \mathrm{q}\right), \lambda\left(\mathrm{AB}^{-1}, \mathrm{q}\right)\right\} \\
& =\max \{\lambda(\mathrm{A}, \mathrm{q}), \lambda(\mathrm{E}, \mathrm{q})\} \\
& =\lambda(\mathrm{A}, \mathrm{q}) . \\
\text { (i.e.) } \lambda(\mathrm{B}, \mathrm{q}) \quad & \leq \lambda(\mathrm{A}, \mathrm{q}) . \\
\text { Hence, } \lambda(\mathrm{A}, \mathrm{q}) & =\lambda(\mathrm{B}, \mathrm{q}) .
\end{aligned}
$$

\subsection{Theorem}

$\lambda$ is an anti Q-fuzzy HX subgroup of a HX group $\vartheta$ if and only if $\lambda\left(\mathrm{AB}^{-1}, \mathrm{q}\right) \leq \max \{\lambda(\mathrm{A}, \mathrm{q}), \lambda(\mathrm{B}, \mathrm{q})\}$, for all $\mathrm{A}, \mathrm{B}$ in $\vartheta$ and $q \in Q$.

\section{Proof}

Let $\lambda$ be an anti Q-fuzzy HX subgroup of a HX group $\vartheta$. Then for all $\mathrm{A}, \mathrm{B}$ in $\vartheta$ and $\mathrm{q} \in \mathrm{Q}$,

$$
\lambda(\mathrm{AB}, \mathrm{q}) \leq \max \{\lambda(\mathrm{A}, \mathrm{q}), \lambda(\mathrm{B}, \mathrm{q})\}
$$

and $\quad \lambda(\mathrm{A}, \mathrm{q})=\lambda\left(\mathrm{A}^{-1}, \mathrm{q}\right)$.

Now, $\lambda\left(\mathrm{AB}^{-1}, \mathrm{q}\right) \leq \max \left\{\lambda(\mathrm{A}, \mathrm{q}), \lambda\left(\mathrm{B}^{-1}, \mathrm{q}\right)\right\}$.
Volume 6-No.11, September 2010

$$
=\max \{\lambda(\mathrm{A}, \mathrm{q}), \lambda(\mathrm{B}, \mathrm{q})\}
$$$$
\Leftrightarrow \lambda\left(\mathrm{AB}^{-1}, \mathrm{q}\right) \leq \max \{\lambda(\mathrm{A}, \mathrm{q}), \lambda(\mathrm{B}, \mathrm{q})\} .
$$

\section{Properties of Lower level subsets of an anti Q-fuzzy HX subgroup}

In this section, we introduce the concept of lower level subset of an anti Q-fuzzy HX subgroup and discuss some of its properties.

\subsection{Definition}

Let $\lambda$ be an anti Q-fuzzy HX subgroup of a HX group $\vartheta$. For any $\mathrm{t} \in[0,1]$, we define the set $\mathrm{L}(\lambda ; \mathrm{t})=\{\mathrm{A} \in \boldsymbol{\vartheta} / \lambda(\mathrm{A}, \mathrm{q}) \leq \mathrm{t}\}$ is called the lower level subset of A.

\subsection{Theorem}

Let $\lambda$ be an anti Q-fuzzy HX subgroup of a HX group $\vartheta$. Then for $t \in[0,1]$ such that $t \geq \lambda(E, q), L(\lambda ; t)$ is a sub HX group of $G$.

\section{Proof}

For all $\mathrm{A}, \mathrm{B} \in \mathrm{L}(\lambda ; \mathrm{t})$, we have,

$$
\lambda(\mathrm{A}, \mathrm{q}) \leq \mathrm{t} ; \lambda(\mathrm{B}, \mathrm{q}) \leq \mathrm{t} .
$$

Now, $\lambda\left(\mathrm{AB}^{-1}, \mathrm{q}\right) \leq \max \{\lambda(\mathrm{A}, \mathrm{q}), \lambda(\mathrm{B}, \mathrm{q})\}$.

$$
\begin{aligned}
\lambda\left(\mathrm{AB}^{-1}, \mathrm{q}\right) & \leq \max \{\mathrm{t}, \mathrm{t}\} \\
\lambda\left(\mathrm{AB}^{-1}, \mathrm{q}\right) & \leq \mathrm{t} . \\
\mathrm{AB}^{-1} & \in \mathrm{L}(\lambda ; \mathrm{t}) .
\end{aligned}
$$

Hence $\mathrm{L}(\lambda ; \mathrm{t})$ is a sub HX group of $\vartheta$.

\subsection{Theorem}

Let $\vartheta$ be a HX group and $\lambda$ be a Q-fuzzy subset of $\vartheta$ such that $\mathrm{L}(\lambda ; \mathrm{t})$ is a sub HX group of $\vartheta$. For $\mathrm{t} \in[0,1] \mathrm{t} \geq \lambda(\mathrm{E}, \mathrm{q}), \lambda$ is an anti Q-fuzzy HX subgroup of $\vartheta$.

\section{Proof}

Let $A, B$ in $\vartheta$ and $\lambda(A, q)=t_{1}$ and $\lambda(B, q)=t_{2}$. 
Suppose $t_{1}<t_{2}$, then $A, B \in L\left(\lambda ; t_{2}\right)$.

As $\mathrm{L}\left(\lambda ; \mathrm{t}_{2}\right)$ is a subgroup of $\mathrm{G}, \mathrm{AB}^{-1} \in \mathrm{L}\left(\lambda ; \mathrm{t}_{2}\right)$.

Hence, $\quad \lambda\left(\mathrm{AB}^{-1}, \mathrm{q}\right) \leq \mathrm{t}_{2}=\max \left\{\mathrm{t}_{1}, \mathrm{t}_{2}\right\}$

$$
\leq \max \{\lambda(\mathrm{A}, \mathrm{q}), \lambda(\mathrm{B}, \mathrm{q})\}
$$

That is, $\lambda\left(\mathrm{AB}^{-1}, \mathrm{q}\right) \leq \max \{\lambda(\mathrm{A}, \mathrm{q}), \lambda(\mathrm{B}, \mathrm{q})\}$.

Hence $\lambda$ is an anti Q-fuzzy HX subgroup of $\vartheta$.

\subsection{Definition}

Let $\lambda$ be an anti Q-fuzzy HX subgroup of a HX group $\vartheta$. The sub HX groups $L(\lambda ; t)$ for $t \in[0,1]$ and $t \geq \lambda(E, q)$, are called lower level sub HX groups of $\lambda$.

\subsection{Theorem}

Let $\lambda$ be an anti Q-fuzzy HX subgroup of a HX group $\vartheta$. If two lower level sub HX groups $\mathrm{L}\left(\lambda ; \mathrm{t}_{1}\right), \mathrm{L}\left(\lambda ; \mathrm{t}_{2}\right)$, for, $\mathrm{t}_{1}, \mathrm{t}_{2} \in[0,1]$ and $t_{1}, t_{2} \geq \lambda(E, q)$ with $t_{1}<t_{2}$ of $\lambda$ are equal then there is no $A$ in $\vartheta$ such that $\mathrm{t}_{1}<\lambda(\mathrm{A}, \mathrm{q}) \leq \mathrm{t}_{2}$.

Proof

$$
\text { Let } \mathrm{L}\left(\lambda ; \mathrm{t}_{1}\right)=\mathrm{L}\left(\lambda ; \mathrm{t}_{2}\right) \text {. }
$$

Suppose there exists $A \in \vartheta$ such that $t_{1}<\lambda(A, q) \leq t_{2}$ then

$$
\mathrm{L}\left(\lambda ; \mathrm{t}_{1}\right) \subseteq \mathrm{L}\left(\lambda ; \mathrm{t}_{2}\right)
$$

Then $\mathrm{A} \in \mathrm{L}\left(\lambda ; \mathrm{t}_{2}\right)$, but $\mathrm{A} \notin \mathrm{L}\left(\lambda ; \mathrm{t}_{1}\right)$, which contradicts the assumption that, $\mathrm{L}\left(\lambda ; \mathrm{t}_{1}\right)=\mathrm{L}\left(\lambda ; \mathrm{t}_{2}\right)$. Hence there is no $\mathrm{A}$ in $\vartheta$ such that $\mathrm{t}_{1}<\lambda(\mathrm{A}, \mathrm{q}) \leq \mathrm{t}_{2}$.

Conversely, suppose that there is no A in $\vartheta$ such that $\mathrm{t}_{1}<\lambda(\mathrm{A}, \mathrm{q}) \leq \mathrm{t}_{2}$

Then, by definition, $\mathrm{L}\left(\lambda ; \mathrm{t}_{1}\right) \subseteq \mathrm{L}\left(\lambda ; \mathrm{t}_{2}\right)$.
Let $\mathrm{A} \in \mathrm{L}\left(\lambda ; \mathrm{t}_{2}\right)$ and there is no $\mathrm{A}$ in $\vartheta$ such that

$\mathrm{t}_{1}<\lambda(\mathrm{A}, \mathrm{q}) \leq \mathrm{t}_{2}$

Hence $\mathrm{A} \in \mathrm{L}\left(\lambda ; \mathrm{t}_{1}\right)$ and $\mathrm{L}\left(\lambda ; \mathrm{t}_{2}\right) \subseteq \mathrm{L}\left(\lambda ; \mathrm{t}_{1}\right)$.

Hence $\mathrm{L}\left(\lambda ; \mathrm{t}_{1}\right)=\mathrm{L}\left(\lambda ; \mathrm{t}_{2}\right)$.

\subsection{Theorem}

A Q-fuzzy subset $\lambda$ of $\vartheta$ is an anti Q-fuzzy HX subgroup of a

HX group $\vartheta$ if and only if the lower level subsets $L(\lambda ; t), t \in$ Image $\lambda$, are HX subgroups of $\vartheta$.

Proof It is clear.

\subsection{Theorem}

Any sub HX group $\mathrm{H}$ of a HX group $\vartheta$ can be realized as a lower level sub HX group of some anti Q-fuzzy HX subgroup of $\vartheta$.

\section{Proof}

Let $\lambda$ be a Q-fuzzy subset and $A \in \vartheta$ and $q \in Q$.

Define,

$$
\lambda(\mathrm{A}, \mathrm{q})= \begin{cases}0 & \text { if } \mathrm{A} \in \mathrm{H} \\ \mathrm{t} & \text { if } \mathrm{A} \notin \mathrm{H}, \text { where } \mathrm{t} \in(0,1] .\end{cases}
$$

We shall prove that $\lambda$ is an anti Q-fuzzy HX subgroup of $\vartheta$.

Let $\mathrm{A}, \mathrm{B} \in \mathcal{\vartheta}$ and $\mathrm{q} \in \mathrm{Q}$.

i. Suppose $A, B \in H$, then $A B \in H$ and $A^{-1} \in H$. $\lambda(\mathrm{A}, \mathrm{q})=0, \lambda(\mathrm{B}, \mathrm{q})=0$, and $\lambda\left(\mathrm{AB}^{-1}, \mathrm{q}\right)=0$. Hence $\lambda\left(\mathrm{AB}^{-1}, \mathrm{q}\right) \leq \max \{\lambda(\mathrm{A}, \mathrm{q}), \lambda(\mathrm{B}, \mathrm{q})\}$.

ii. $\quad$ Suppose $\mathrm{A} \in \mathrm{H}$ and $\mathrm{B} \notin \mathrm{H}$, then $\mathrm{AB} \notin \mathrm{H}$ and $\mathrm{AB}^{-1} \notin \mathrm{H}$. $\lambda(\mathrm{A}, \mathrm{q})=0, \lambda(\mathrm{B}, \mathrm{q})=\mathrm{t}$ and $\lambda\left(\mathrm{AB}^{-1}, \mathrm{q}\right)=\mathrm{t}$. Hence $\lambda\left(\mathrm{AB}^{-1}, \mathrm{q}\right) \leq \max \{\lambda(\mathrm{A}, \mathrm{q}), \lambda(\mathrm{B}, \mathrm{q})\}$. 
iii. Suppose $\mathrm{A}, \mathrm{B} \notin \mathrm{H}$, then $\mathrm{AB}^{-1} \in \mathrm{H}$ or $\mathrm{AB}^{-1} \notin \mathrm{H}$. $\lambda(\mathrm{A}, \mathrm{q})=\mathrm{t}, \lambda(\mathrm{B}, \mathrm{q})=\mathrm{t}$ and $\lambda\left(\mathrm{AB}^{-1}, \mathrm{q}\right)=0$ or $\mathrm{t}$.

Hence $\lambda\left(A^{-1}, q\right) \leq \max \{\lambda(A, q), \lambda(B, q)\}$.

Thus in all cases, $\lambda$ is an anti Q-fuzzy HX subgroup of $\vartheta$.

For this anti Q-fuzzy HX subgroup, $\mathrm{L}(\lambda ; \mathrm{t})=\mathrm{H}$.

\section{Remark}

As a consequence of the Theorem 4.3 and 4.4, the lower level HX subgroups of an anti Q-fuzzy HX subgroup A of a HX group $\vartheta$ form a chain. Since $\lambda(E, q) \leq \lambda(A, q)$ for all A in $\vartheta$ and $q \in Q$, therefore $\mathrm{L}\left(\lambda ; \mathrm{t}_{0}\right)$, where $\lambda(\mathrm{E}, \mathrm{q})=\mathrm{t}_{0}$ is the smallest and we have the chain :

$\{\mathrm{E}\} \subset \mathrm{L}\left(\lambda ; \mathrm{t}_{0}\right) \subset \mathrm{L}\left(\lambda ; \mathrm{t}_{1}\right) \subset \mathrm{L}\left(\lambda ; \mathrm{t}_{2}\right) \subset \ldots \subset \mathrm{L}\left(\lambda ; \mathrm{t}_{\mathrm{n}}\right)=\vartheta$, where $\mathrm{t}_{0}<\mathrm{t}_{1}<\mathrm{t}_{2}<\ldots \ldots<\mathrm{t}_{\mathrm{n}}$

\section{REFERENCES}

[1] Kim.K.H., Yun.Y.B., on fuzzy R- subgroups of near rings, J.fuzzy math 8 (3) (2000) 549-558.

[2] Kim.K.H., Yun.Y.B., Normal fuzzy R- subgroups in near rings, Fuzzy sets systems 121 (2001) 341-345.

[3] Kim.K.H., on intuitionistic Q- fuzzy semi prime ideals in semi groups, Advances in fuzzy mathematics, 1 (1) (2006) 15-21.
[4] Li Hongxing, HX group, BESEFAL,33(1987), pp(31-37).

[5] Luo Chengzhong, Mi Honghai , Li Hongxing, Fuzzy HX group , BUSEFAL.

[6] Muthuraj.R., Sithar Selvam.P.M., Muthuraman.M.S., Anti Q-fuzzy group and its lower Level subgroups, International journal of Computer Applications (0975-8887), Volume 3- no.3, June 2010, 16-20.

[7] Muthuraj.R., Sridharan.M., , Muthuraman.M.S., and Sithar Selvam.P.M., Anti Q-fuzzy BG-idals in BG-Algebra, International journal of Computer Applications (0975-8887),Volume 4, no.11, August 2010, 27-31.

[8] Muthuraj.R., Sridharan.M., and Sithar Selvam.P.M., Fuzzy BG-ideals in BG-Algebra, International Journal of Computer Applications (0975-8887) Volume 2-No.1 may 2010.

[9] Osman kazanci, sultan yamark and serife yilmaz "On intuitionistic Q - fuzzy R-subgroups of near rings” International mathematical forum, 2, 2007 no. 59, 2899-2910.

[10] Palaniappan.N., Muthuraj.R., , Anti fuzzy group and Lower level subgroups, Antartica J.Math., 1 (1) (2004) , 71-76.

[11] Rosenfeld.A., fuzzy groups, J. math. Anal.Appl. 35 (1971), 512-517.

[12] Solairaju.A., and Nagarajan.R., “ Q- fuzzy left R- subgroups of near rings w.r.t T- norms", Antarctica journal of mathematics.5, (1-2), 2008.

[13] Solairaju.A., and Nagarajan.R., A New Structure and Construction of Q-Fuzzy Groups, Advances in fuzzy mathematics, Volume 4, Number 1 (2009) pp.23-29. 